\title{
A EMERGÊNCIA DA INFÂNCIA
}

\section{José Gonçalves Gondra*}

RESUMO: Neste artigo, procuro analisar três aspectos que funcionarão como ferramenta para pensarmos a emergência da infância. Em um primeiro momento, refiro-me a algumas experiências-limite da vida, na medida em que elas ajudam a arranhar as visões que naturalizam a vida e a infância, em especial aquelas forjadas no interior do campo médico. Na sequência, tento demonstrar que a ideia de infância não pode ser pensada no exterior das instituições que lhe são associadas, como a casa e a escola. Por fim, procuro chamar atenção para o fato de que a institucionalização geral da infância se encontra profundamente acoplada a projetos de governo da população, inclusive da "população infantil", projeto este que, por sua vez, se vê ancorado em saberes oriundos da demografia, da higiene pública e do urbanismo, por exemplo.

Palavras-chave: Infância; História da Infância; História da Educação.

\section{THE EMERGENCE OF CHILDHOOD}

ABSTRACT: In this article, I try to look at three aspects which will serve as a tool to ponder over the emergence of childhood. At first, I refer to some limit of life experiences, in a way that they help scrape the visions that naturalize life and childhood, in particular those forged within the medical field. Next, I try to demonstrate that the idea of childhood cannot be disconnected from associated institutions, such as home and school. Finally, I try to draw the attention to the fact that the children's general institutionalization is deeply bound to government projects aimed at the population, including the so-called "child population", a project which, in turn, is anchored on the knowledge of demography, public hygiene and urbanism, for instance.

Keywords: Childhood; Children's History; History of Education.

* Doutor em Educação pela Universidade de São Paulo (USP); Professor Adjunto da Universidade do Estado do Rio de Janeiro (UERJ); Pesquisador do Conselho Nacional de Desenvolvimento Científico e Tecnológico (CNPq) e da Fundação de Amparo à Pesquisa do Estado do Rio de Janeiro (FAPERJ). E-mail: gondra@oi.com.br 
Nos debates sobre a infância, é possível reconhecer a presença de um traço comum. Trata-se de conceber "a infância não como um intervalo cronológico natural, e sim como um período da existência humana constituída por um sistema normativo, que lhe atribui características, formas, competências e funções, precisas ou fluidas, ancoradas em sistema de ordenações, que cada grupo social relaciona ao seu sistema valorativo"1.

Apanho essa definição para me deter no traço comum que tem marcado o debate, para fortalecer essa afirmação. Trata-se de pensar a infância como algo forjado, interessando explorar o próprio processo que termina por delinear a força e os limites daquilo que o termo infância pretende descrever. No exame desse processo, neste exercício de pensar, vou privilegiar o exame de um sistema normativo que, do meu ponto de vista, marcou e ainda marca profundamente o saber que partilhamos sobre essa "etapa da vida", ideia que também pretendo pensar, mas que, neste momento, deixo em suspenso para retomá-la ao longo da exposição. A que sistema normativo me refiro? Com que tipo de saber pretendo operar para pensar a "emergência da infância"?

Neste caso, vou me deter no modo como o saber médico organizou uma representação da vida e da infância, construindo uma grade de inteligibilidade para ambas que, em muito, colonizou nosso pensamento, instaurando uma espécie de verdade no que se refere à vida e à infância, em relação à qual é muito difícil instaurar uma diferença. Vou tentar demonstrar que fomos capturados por essa ordem de saber, por seus jogos de poder, o que faz com que tenhamos em relação a nós mesmos condutas alinhadas às representações fabricadas no interior do campo médico-higiênico.

Antes de prosseguir, façamos uma ligeira incursão no título sugerido para este texto. Quando me refiro à "emergência da infância", procuro jogar com o duplo sentido da expressão. Em um primeiro sentido, é possível associar o termo emergência à ideia de uma situação crítica, limite, que requer ações urgentes. Nesse sentido, poderíamos, invertendo a ordem dos termos, fixar mais essa acepção quando ouvimos ou repetimos a tese da infância como problema a ser enfrentado de modo urgente, e o caráter emergencial desse enfrentamento. Em um segundo sentido, associamos o termo emergência à ideia de manifestar-se, mostrarse. Emergir corresponderia a uma espécie de aparecimento, nascimento, surgimento, criação, invenção. 
Do meu ponto de vista, ao operar com esse duplo sentido - da urgência e da invenção -, instaura-se uma ordem em que a primeira compreensão, uma ação emergencial/urgente voltada para a infância, fica condicionada, regulada, marcada pela segunda. Ora, falar de uma "urgência" da infância só se torna possível a partir de seu surgimento, que, por sua vez, se encontra associado à instituição e à legitimação de uma concepção de vida recortada em etapas, cada qual com seus marcadores/ indicadores temporais, articuladas, por sua vez, a um esquema classificatório que procura instituir um jogo de reconhecimento de atributos comuns a cada uma das etapas da vida. Classificação que, ao reconhecer o comum, chancela e autoriza determinados procedimentos, faz aparecerem, por exemplo, saberes, agentes, materiais, métodos e instituições especializadas em cada uma das etapas da vida. [Hoje, com a mudança do perfil etário da população, ao que assistimos, com a chamada terceira idade, senão isso? E por que isso vem sendo feito nesses termos? Ao lado da qualidade de vida que se persegue para essa "etapa" de uma vida que se prolonga, que outros interesses são associados? O que se pretende com esse tipo de investimento cada vez mais maciço? Extensão do corpo produtivo? Novas rentabilidades? Consumo? Voto? Que novas utilidades se espera da vida alongada?]

Após essa espécie de introdução, daqui para frente, passo a tratar de três aspectos que funcionarão como ferramenta para pensarmos a emergência da infância. Em um primeiro momento, vou me referir a experiências-limite da vida e como elas ajudam a arranhar as visões que naturalizam a vida e a infância. $\mathrm{Na}$ sequência, vou tentar demonstrar que a ideia de infância não pode ser pensada no exterior das instituições que lhe são associadas, como a casa e a escola. Por fim, vou chamar atenção para o fato de que a institucionalização geral da infância se encontra profundamente acoplada a projetos de governo da população, inclusive da "população infantil". Esse é o roteiro geral da reflexão proposta.

Ao privilegiar o exame do discurso médico, é importante sublinhar que a representação etapista da vida não se constitui em um monopólio dessa ordem, pois se encontra ancorada, ligada, amarrada em ordens de saber bem diversificadas. Trata-se de uma representação que se capilarizou, sendo partilhada por campos distintos. Onde a ideia de uma vida em segmentos pode ser percebida? 
Ao observarmos os sacramentos da Igreja Católica, percebemos que cada um se encontra associado a diferentes etapas da vida, como forma de marcar a inscrição e a manutenção dos sujeitos nessa ordem. Inicia-se com o batismo, impondo um pertencimento a um sujeito que não tem vontade, operando em um calendário da vida, com ciclos de repetição, nos quais o pertencimento à ordem religiosa é testado, confirmado e que deve ter continuidade até o fim da vida, com o sacramento final da extrema-unção.

No campo jurídico, a vida também é fortemente segmentada, instituindo limites temporais que podem livrar, suavizar ou instaurar a responsabilidade penal aos diferentes sujeitos. Tema que tem retornado, com alguma frequência, sobretudo nos casos de crimes espetacularizados que envolvem jovens e os debates que tais acontecimentos suscitam em torno da maioridade penal. Recoloca-se a questão: com que idade os sujeitos podem responder pelos seus atos, quando é que aparece a capacidade de discernimento?

Ora, essa chave também parece trabalhar no registro de uma vida segmentada, de um gradiente que termina por arbitrar uma separação entre o tempo da razão ou discernimento - próprio do mundo adulto - e o tempo da infância, tempo de ausência ou de fraqueza da razão.

O mundo do trabalho e o campo militar também forneceriam elementos para se pensar a participação dessas forças na definição de idades da vida. Os debates sobre o trabalho infantil e a obrigatoriedade do serviço militar parece que se encontram associados a determinados marcos temporais da vida que, atingidos, permitiriam o ingresso no mundo do trabalho e nas forças militares.

Que outras forças concorrem para fortalecer a cronologia da vida? Não se trata de compor uma lista exaustiva. Vou apanhar apenas mais dois exemplos: o campo médico e o campo pedagógico. No primeiro caso, as prescrições amplas sobre alimentos, vestimentas, tipos de atividades, desenvolvimento físico, intelectual e moral dos sujeitos encontrase fortemente associada à forma como o saber médico se institucionalizou, o tipo de saber disponível em cada momento e as disputas que terminaram por soterrar determinadas representações e legitimar outras.

Veja-se, por exemplo, as formas de classificação da vida gestadas na esfera do campo médico, como as de Hallé (cinco etapas, com subdivisões e diferenciação de acordo com o sexo), Daubeton (seis etapas), 
Becquerel (sete etapas) e inúmeros outros tratadistas da higiene ${ }^{3}$. Ao partilhar e legitimar a doutrina da segmentação, esses homens da ciência fazem variar os pontos e os números de segmentos da vida. Segmentação que se pretende manter a qualquer custo, inclusive em casos atípicos e extremos, como o é o das chamadas crianças-fera ou homens-natureza. Como vocês sabem, Jean de Liége, o menino-urso da Lituânia ${ }^{4}$; Hesse, o meninolobo ; o menino-carneiro irlandês ${ }^{6}$; a garota de Kranenburg7 ${ }^{7}$ Peter, o Selvagem, de Hanover ${ }^{8}$; e a menina selvagem de Champagne ${ }^{9}$ são exemplos conhecidos de "crianças-selvagens" que, desde os primeiros registros na Idade Média, põem em xeque a verdade que a civilização ocidental (e o campo médico) vem estabelecendo em relação à vida. Desde Carl Von Linné, esses seres vêm sendo caracterizados pela ausência de linguagem, pela quadrupedia e pela hirsutia (abundância de pelos). No entanto, os diagnósticos e as ações junto a essas vidas extraordinárias nem sempre foram consensuais ${ }^{10}$, como no conhecido debate entre Philippe Pinel e seu discípulo Jean Itard a respeito do "Selvagem de Aveyron".

Uma pequena digressão neste caso, pois ele é ilustrativo do debate sobre o mito construído a respeito da natureza da vida e da naturalização da infância. Digressão que também parece ser interessante, dada a facilidade de acesso aos relatórios do Dr. Itard e ao belo filme que trata desse caso, dirigido por François Truffaut, intitulado $A$ criança selvagem, de 1969. O que se passa nesse caso? Como ele pode ajudar a pensar a emergência da infância como fração da vida e a sua naturalização?

O menino conhecido como "selvagem de Aveyron" foi encontrado, pela primeira vez, no final do século XVIII, por volta de 1798, e estima-se que tinha entre 11 ou 12 anos. Ele se alimentava de grãos e raízes, trotava ou galopava, não falava, muito menos lia ou escrevia.

O médico Jean Itard, divergindo do diagnóstico de seu mestre, que classificara o menino como idiota, não suscetível de espécie alguma de sociabilidade e instrução, termina por obter apoio do governo francês para desenvolver uma experiência educativa, na tentativa de inseri-lo no mundo dos homens, no mundo civilizado. "Adotado pela pátria", o menino é entregue aos cuidados do Dr. Itard durante cerca de 10 anos, período no qual é submetido a inúmeras experiências no que se refere a alimentação, locomoção, educação de alguns sentidos, sobretudo tato, olfato, visão, paladar e audição. 
No que se refere à educação propriamente dita, Dr. Itard partilha do código geral da higiene e procura desenvolver a educação física, moral e intelectual do menino-natureza. Ensina o bipedismo, movimentos de apreensão e manejo de determinados objetos, a se sentar, vestir, dormir, etc. Do ponto de vista moral, os afetos são estimulados e também o desenvolvimento do sentimento de justiça, a partir de experiências regulares que o médico desenvolve, sendo algumas delas descritas nos dois relatórios que apresenta ao governo francês (1801 e 1807). No que se refere à educação intelectual, a rotina das experiências também oscila entre o sucesso e o insucesso das tentativas do médico. Em suas palavras: "ao mesmo tempo em que a alma de nosso Selvagem se abre para algumas das alegrias do homem civilizado, ainda assim ela continua a mostrar-se sensível à sua vida primitiva" (BANCKS-LEITE; GALVÃO, 2000, p. 221).

No projeto de fazer o jovem ingressar nas alegrias do mundo civilizado, Dr. Itard narra seus esforços para desenvolver a memória, a atenção e a linguagem, obtendo sucessos significativos em relação aos dois primeiros e um fracasso importante no que se refere à aquisição da fala, o que faz com que o médico vá perdendo as esperanças em seu projeto educativo. Ao morrer, em 1928, com cerca de 40 anos, o homemnatureza ainda não falava e era considerado um semi-idiota.

A sexualidade do garoto selvagem é outro ponto que se encontra no arco das preocupações educativas do médico, que, em relatórios, por mais de uma vez, aponta sinais de manifestação da sexualidade do menino ou, como ele assinala, "os movimentos impetuosos de uma puberdade muito pronunciada" ou "efervescência de seus órgãos" (BANCKSLEITE; GALVÃO, 2000, p. 225-226). No entanto, esse é um aspecto em relação ao qual procura manter distância, ainda que declare ter recorrido ao uso de sangrias, com muitas reservas à técnica empregada, para obter um "pouco de calma" de seu aluno-paciente.

Por que fazer essa curta digressão? Ora, porque ela possibilita perceber o homem como elemento da cultura ${ }^{11}$, podendo ser igualmente lida como expressão de uma crítica sensível ao modo como se reparte a vida e das características atribuídas a cada uma das partes em que ela é dividida. No caso do jovem, apesar de ter se desenvolvido biologicamente, na ausência de contato com o mundo dos homens, seus órgãos sensitivos construíram outra orientação, a linguagem não se desenvolveu, como 
também se desenvolveram de forma diferenciada os órgãos de locomoção. Experiência de vida que também fez com que a sexualidade se manifestasse de modo particular. Se esses são alguns elementos que ajudam a pensar o que não é natural no homem, a crítica ao mundo dos adultos se vê reforçada quando observamos a suspeita do que teria proporcionado ao menino a experiência de uma vida isolada. No caso, a marca do abandono, a partir da hipótese de que "O garoto selvagem" teria sido abandonado em uma floresta, "o maior orfanato do mundo", como ironiza Aroles (2007), após uma tentativa de infanticídio, fato que encontra apoio nas características de uma cicatriz presente no pescoço do menino, cuja descrição, conforme consta no relatório do Dr. Itard, reforça essa hipótese.

O caso do garoto selvagem parece inverter e suspender a cronologia da vida, na medida em que chama a atenção para a força das experiências culturais na definição das habilidades sensitivas, físicas, morais, intelectuais, afetivas e sexuais dos indivíduos. $\mathrm{O}$ aparecimento e o desenvolvimento das potências da vida parece não obedecer ao doce e monótono ritmo do relógio e de nossa forma tradicional de contabilizar o tempo. Portanto, o caso ajuda a pensar no arbitrário das idades da vida, no tipo de saber que constrói e nas instituições que apoiam e se apoiam nessa verdade. Uma delas é o próprio Estado moderno. Não é à toa que, ao mesmo tempo em que esse caso ganha notabilidade na sociedade francesa, um dos expoentes da revolução escrevia memórias sobre a instrução pública, base para seus projetos reformadores, nas quais ressalta a necessidade de uma educação formal de crianças, jovens e trabalhadores. A quem me refiro? Condorcet... No que se refere à criança, o que ele propõe? Um amplo e refinado projeto de escolarização, incidindo sobre as propriedades gerais da forma escolar de educação. No que se refere a uma das questões obrigatórias - quando iniciar e por quanto tempo prolongar esse tipo de experiência, Condorcet afirma que a mesma deveria ter início aos 9 anos, em três ciclos de quatro anos cada um, sendo concluída aos 21 anos. Nesse projeto, o primeiro ciclo corresponderia à educação comum.

Esse programa e essa repartição vêm apoiados e reforçam ainda mais o caráter estratificado da escola e da vida, ao mesmo tempo em que definem um tempo de competência sobre a vida que seria de responsabilidade da casa e outro, da escola, diga-se, do Estado; cada vez mais 
interessado em disciplinar os corpos e as populações, como forma de se legitimar e de se reproduzir. Nesse sentido, a escola parece ser uma agência talhada para agir nessas duas pontas. Tornada obrigatória e lutando para uma obrigatoriedade cada vez mais extensa (não apenas em número de anos, mas também de dias do ano, da semana e de horas do dia), os discursos a respeito da forma escolar ideal vão proliferar e fazer da mesma uma peça estratégica na afirmação do Estado e na dinâmica de governo por ele praticada.

No Brasil, o Dr. Afrânio Peixoto, um baiano ilustrado que ocupou postos de saber e poder variados, também participou do debate sobre a escola, na condição de diretor da escola normal da capital, diretor geral de instrução, professor universitário na área de higiene e medicina legal, professor de história da educação do Instituto de Educação do Rio de Janeiro e autor de inúmeras obras de literatura, poesia e teatro. Transitando nesses lugares de saber e de poder, no que se refere às idades da vida e à idade da escola, o médico está profundamente sintonizado com a doutrina de sua ordem. É necessário repartir a vida e prescrever para cada fase medidas próprias que reconheçam e solidifiquem a crença em uma vida segmentada. No caso da idade da escola, trabalha com a tese de que essa ação deve ter início aos seis ou sete anos. Antes disso, dado o modo como descreve a família, a mulher e a criança, esta deveria ficar sob os cuidados dos pais.

Já Moncorvo Filho, um contemporâneo e leitor de Afrânio Peixoto, abria uma frente de ação voltada, sobretudo, para as famílias mais pobres. No caso, o vetor da filantropia e da assistência invadia para baixo a cronologia da vida, sobretudo das famílias pobres. Descritas a partir de um conjunto de práticas que deveriam ser combatidas, as famílias pobres deveriam ser educadas ou, no limite, a criança pequena deveria ser retirada desse tipo de convívio, com vistas a se assegurar seu crescimento em ambiente sadio. Esse parece ter sido o tom geral dos esforços voltados para a criação dos Institutos de Proteção à Infância e das campanhas que promove para a transformação dos hábitos viciosos, em especial da família pobre.

Por exemplo, ao constituir a mortalidade infantil como problema, o Dr. Moncorvo Filho partilha da ideia de que não bastava combater abortos e infanticídios. Para ele, a vida das crianças seria assegurada com a ampliação do tempo de vigilância sobre os adultos. Desse modo, a 
ignorância dos pais, sobretudo das mães pobres, também deveria ser objeto de governo, patrocinado pelo Estado ou não, de modo a assegurar a viabilidade de um projeto para a Nação, para o qual o saber médico reivindicava a condição de pilar fundamental. No entanto, ao olhar para fora e para o Brasil, especialmente para sua capital, o que via?

Via que, no mundo civilizado, operava-se aquilo que ele chama de uma verdadeira revolução social visando à preservação da infância, inclusive com a criação de não pequeno número de obras filantrópicas tais como dispensários modelares, creches, gotas de leite, ligas, mutualidades e hospitais, entre tantas outras. Aqui, segundo ele, se observavam uma displicência e um desinteresse desoladores, completamente indiferentes a todo movimento progressista e humanitário. Ao lado dessa constatação, o fundador do IPAI (1899), com o "demorado estágio" no serviço de crianças da Policlínica Geral do Rio de Janeiro ${ }^{12}$, admitia ter tomado conhecimento da "dolorosa situação" em que se encontrava a infância "fraca, doente, maltratada, abandonada ou faminta" na Capital da República:

Cada dia mais se multiplicavam os quadros de desolação a que assitiamos: creanças vivendo asphyxiadas no deleterio confinamento das estalagens e no ambiente infecto das casas de commodos, a serem dizimadas em numero assustador pelos males tão conhecidos dos clinicos brasileiros, sobretudo pelas doenças do apparelho digestivo e a tuberculose - hydra devastadora e traiçoeira, - tudo, aggravado pela herança alcoolica ou luetica, pela miseria e pela fôme, num deploravel ambiente de ignorancia e de analphabethismo! (MONCORVO FILHO, 1931, p. 4)

Como se pode perceber, a condição social e o diagnóstico médico relacionados à pobreza fazem o limite de idade deslizar para baixo, autorizando, com isso, a entrada do Estado no domínio das casas, sobretudo das famílias pobres, descritas como ignorantes e incapazes. Representadas nesses termos, serão progressivamente desautorizadas a conduzir seus filhos. Conduta esta que vai ser deslocada para o conjunto de instituições que o médico brasileiro via florescer no exterior, às quais dedicou parte expressiva de sua vida.

Ora, a definição das competências próprias a cada etapa da vida parece ter efeito normativo muito intenso na regulação das instituições responsáveis pelo atendimento da criança, seja a casa/família, seja a escola 
ou, ainda, as outras instâncias de socialização, como as assinaladas pelo Dr. Moncorvo Filho. Se esses elementos ajudam a pensar o funcinamento do campo médico, o que se processa no campo pedagógico?

No caso do campo pedagógico, o que se evidencia é sua colonização pelo saber médico-higiênico e por suas derivações mais recentes, que, cada vez mais especializadas, segmentam não apenas as idades da vida, mas cada uma das manifestações dos sujeitos, invadindo o saber pedagógico de um vocabulário e de uma dependência que enfraquecem, despotencializam cada vez mais a ação dos professores e das famílias, sobretudo as mais pobres e as mais afastadas do capital cultural que procura englobá-las, dominá-las, enfim, normalizá-las.

Ao ser invadido por essa espécie de saber sobre a vida, o campo pedagógico passa a ser pautado pelas prescrições derivadas do campo médico-higiênico, nas diferentes formas em que elas se manifestam. Contudo, a adesão a determinados princípios faz combinar, articular outros elementos, como a própria configuração das famílias, as funções sociais exercidas por homens, mulheres e crianças, a reconfiguração dos campos e das cidades e a capacidade de se executar algumas determinações decorrentes da ciência médica, sobretudo quando elas se voltam e recobrem as iniciativas escolares criadas e mantidas pelo poder público.

Um pequeno exemplo, desdobrado em um questionário em torno do tempo escolar ou de uma representação expandida desta ideia, que vem precedida de uma decisão e da construção de uma necessidade: a do dever de se educar o homem. Decisão tomada, caberia estabelecer: Quando deve ter início a experiência de escolarização? Quanto tempo deve durar? Quando deve ser encerrada? Quantos dias do ano devem ser ocupados pela escola? Quantos dias da semana? Quantas horas do dia e de acordo com que tipo de repartição, distribuição? Esse questionário só se tornou possível quando se procurou enfrentar o desafio de escolarizar a todos. Desafio que, por sua vez, torna obrigatório o questionário, ainda que as respostas a ele estejam longe de ser gerais e universais. Ao lado disso, quando a resposta para cada uma dessas perguntas é alterada, isso provoca impacto expressivo no funcionamento das escolas e da sociedade.

Todos devem se lembrar da intervenção vigorosa da Revolução Francesa no calendário. Por mais de dez anos, ela teve calendário próprio, que procurou tomar distância do calendário cristão. A Revolução inaugurou uma contagem, em que o ano I correspondia ao ano dela e, assim, 
estabelecia o início de uma nova contabilidade, impondo outro marco que deveria se constituir em referência para uma nova história. Se esse fato, por si só, chama a atenção para o projeto daquela Revolução, sua consistência se faz presente na renomeação dos meses e no desaparecimento da ideia de semana - unidade temporal profundamente cristã, como todos sabemos -, que a Revolução Francesa procurou substituir pela noção de "década". Desse modo, o mês seria organizado em torno de três "décadas", e não mais de quatro semanas. Todos sabem os desdobramentos da Revolução Francesa e que ela culminou com vários retornos e a restauração, inclusive, do calendário cristão. Eis um pequeno exemplo do caráter histórico ou, se preferirem, cultural do tempo, que, ao se refazer o modo de contabilizá-lo, nos leva a tomar distância da frieza dada pela translação de corpos no céu.

Voltando ao nosso inquérito a respeito dos elementos que configuram a experiência escolar, cabe ressaltar que afirmar o início da escolarização formal aos 9 anos e sugerir que a educação comum obrigatória deve ser de quatro anos, como queria Condorcet, no auge da Revolução Francesa, distribui responsabilidades específicas para a casa e para o governo. Reduzir ou aumentar esse período promove rebatimentos evidentes nas instituições assinaladas e nas outras que a elas se encontram associadas. No caso do Estado, qualquer redução do "tempo escolar" implica menos gastos com escolas, professores, alunos, etc. De outra parte, qualquer ampliação desse tempo provoca efeitos orçamentários nada desprezíveis. É com essa aritmética que o Estado opera para poder governar e aderir ou não às reconsiderações sobre as idades da vida, da idade escolar, da imposição da obrigatoriedade e aos remanejamentos que tais medidas instauram no seio das famílias. Nesse caso, é digno de nota o crescimento dos discursos relativos à atenção à criança pequena, discursos decorrentes da pobreza (como vimos, por exemplo, no caso do Moncorvo Filho), de novas demandas sociais provocadas pelas reconfigurações familiares e da presença feminina cada vez mais intensa no trabalho fora da casa. O que está em curso? Um novo desenho da relação com a pobreza, com o tempo da casa e dos papéis sociais desempenhados por homens, mulheres e crianças.

Ora, o governo da criança pobre e as reconfigurações sociais em curso terão impacto importante nas descrições da infância e do tipo de atenção que ela passa a requerer. Novos investimentos, novas instituições, 
novos profissionais e um cinturão de serviços passam a ser organizados em virtude de um funcionamento da sociedade não mais assentado no modelo familiar em que o homem trabalhava fora e a mulher dirigia o espaço da casa. Os discursos sobre a pobreza e as reconfigurações no mundo do trabalho e da casa serão responsáveis por deslocamentos na ordem do discurso que passarão a admitir e defender o trabalho regular junto à criança pequena desde "a mais tenra idade", para usar uma expressão do Fénelon. Portanto, temos aqui um pequeno e conhecido indício do impacto das transformações do mundo do trabalho e de reorganização dos núcleos familiares em novas demandas que vão ser forjadas no que se refere ao trabalho com as crianças.

Com o alargamento do tempo escolar, com a institucionalização cada vez mais "precoce" da criança - o termo não é bom pelo suposto que sugere de haver um tempo justo, bom, ideal para o início dessa forma de experiência -, o que se processa, o que se evidencia? Para tentar aquecer nosso debate (e me encaminhar para as partes finais desta exposição), vou tentar suspender representações românticas sobre a escola e a criança. Neste exercício, procurei ancorar minhas reflexões apoiado em algumas considerações do Michel Foucault. Nessa linha, o ingresso cada vez mais cedo das crianças na escola (não desconheço o debate sobre a designação da instituição voltada para o atendimento da criança pequena, mas dadas as propriedades gerais da mesma, vou adotar o termo escola, posto que as instituições de educação da infância se caracterizam, salvo engano, por uma hierarquização e pela diferenciação dos saberes horizontal e verticalmente, estratificação dos agentes - gestores, fiscais, professores, familiares e alunos -, localização e arquitetura cada vez mais específica, delimitação do tempo de ação e sua rotinização, determinação do alcance (gênero, idade, condição social, saúde, duração), estabelecimento do método - para ensinar e castigar e, por fim, fabricação de materiais, confecção de mobiliário e uniformes próprios. Esse ingresso cada vez mais precoce, uma entrada que quase coincide com o nascimento, sugere um alargamento da disciplina e do biopoder. Extensão que, se quiserem, mas não poderemos avançar aqui hoje, se prolonga e se manifesta, por exemplo, em campanhas voltadas para o estabelecimento do bom casal, do ponto de vista higiênico. Nesse sentido, um conjunto de regras relativas ao sangue, à idade, ao peso, às alturas e raças, por exemplo, deveria ser observada para evitar a degeneração do homem como espécie. 
Nesse sentido, uma ação sobre a criança deveria se instalar antes de seu aparecimento, preventivamente, evitando, assim, o aparecimento dos males. Isso poderia ser visto como algo diferente de uma ação disciplinar?

Antes de prosseguir nesse ponto, que, imagino, deve ser polêmico e objeto de tensões, é necessário desenvolver minimamente a ideia de disciplina e de biopoder. Afinal, o que esses termos recobrem? O que pretendem descrever? No caso de disciplina, também é possível trabalhar com, pelo menos, duas acepções largas: uma que remete a uma ordem de saber e, outra, aos jogos de poder.

No primeiro caso, trata-se de uma forma discursiva que visa a controlar/limitar a produção de novos discursos. Trata-se de um projeto voltado para a disciplinarização dos saberes, o que leva a compreender a Enciclopédie e a criação das grandes escolas e universidades como mecanismos articulados a essa finalidade e que vão fermentar o aparecimento de campos disciplinares e orientar suas transformações ${ }^{13}$. Uma segunda acepção de disciplina é associada à ordem do poder. Trata-se, nesse caso, de um conjunto de técnicas em virtude das quais os sistemas de poder têm por objetivo e resultado a singularização dos indivíduos. Volta-se para o corpo e a singularização dos indivíduos. Remete a uma forma de exercício do poder que tem por objeto os corpos, seus detalhes, sua organização interna e que pretende atingir, com isso, a eficácia máxima de seus movimentos.

Se é possível observar essa ramificação de sentido para o caso da ideia de disciplina, o mesmo não se pode dizer do seu funcionamento, no qual essas pontas se juntam, articulando saber e poder, como condição de fazer emergir determinadas coisas e aterrar outras, como é o caso da própria ideia de infância e das instituições a ela correlatas e que passam a sustentar determinadas práticas voltadas para esse segmento da vida.

Ao trabalhar no registro de que a expansão da ação sobre a criança pequena encontra-se associada à dilatação do poder disciplinar, cabe lembrar os mecanismos complexos que o fazem funcionar e as finalidades que pretende atingir. Para Foucault, a disciplina objetiva tornar os corpos dóceis e, para tanto, pratica a arte das suas distribuições, de acordo com uma lógica celular, controla a atividade, organiza as gêneses e a composição das forças dos corpos, para se obter o máximo deles. Para tanto, para bem adestrar o corpo, para rentabilizá-lo ao extremo, organiza uma vigilância hierárquica, emprega sanções normalizadoras e submete o 
sujeito a procedimentos examinatórios regulares e quase perpétuos. Esse modelo teria alcançado sua formulação mais refinada no esquema panóptico, que deveria servir de inspiração para a organização e o funcionamento do conjunto das instituições disciplinares, como o exército, o hospício, o quartel, a prisão, os asilos e a escola ${ }^{14}$.

Ora, tudo parece indicar que instituições, saberes, sujeitos, materiais e métodos voltados para a educação da infância estão muito próximos da perspectiva disciplinar, inclusive no surgimento dos contrapoderes que podem demandar novos arranjos disciplinares, nos termos concebidos por Michel Foucault. Agir sobre "as fibras moles do cérebro", sobre um corpo que não se movimenta, que não julga e não tem vontade tem por objetivo intensificar a utilidade dos corpos. No entanto, as reconfigurações do mundo da casa e do trabalho não cessam de gerar coisas novas, novas necessidades, como é, por exemplo, o caso da educação infantil. Essa nova modalidade de educação não deve ser lida apenas na chave da disciplina, esse conjunto das minúsculas invenções técnicas que permitiram fazer crescer a extensão útil dessas e de outras multiplicidades, fazendo diminuir os inconvenientes do poder, que deve regê-las, justamente para torná-las úteis.

A institucionalização maciça da criança pequena nos obriga a pensar esse fenômeno de massa como parte de uma tecnologia de governo. Nesse sentido, as crianças também são passíveis de serem descritas em termos de população - esse novo corpo múltiplo, mas quantificável, localizável, mensurável. Trata-se de saber quantos são? Onde estão? Que idades possuem? Qual seu sexo? Que cor possuem? De onde provêm? Nessa chave, a ideia de infância passa a estar associada à de população infantil - uma ideia muito recente, que, no Brasil, tem apenas algumas décadas.

Pensar a infância também em termos de população supõe que se pense medidas globais para essa massa, o que vai exigir a racionalização das práticas governamentais dos aspectos próprios a esse conjunto de "pequenos seres". Racionalização da população infantil que vai, por seu turno, exigir a intensificação de saberes relativos à demografia (taxas de reprodução, fecundidade, nascimentos e mortalidade infantil e localização das crianças - deslocamento e fixação), à higiene pública (doenças infantis - natureza, extensão, duração e intensidade) e ao urbanismo (planejamento das cidades, tendo em vista a população infantil, os equipamentos 
urbanos - definição, localização e funcionamento), por exemplo.

Portanto, por essa tripla evidência - dos saberes ligados à demografia, à medicina e à ciência das cidades, - é possível pensar as ações celulares que, combinadas com as medidas globais associadas às novas racionalizações em curso, pretendem assegurar rentabilidade máxima dos corpos e regulação/equilíbrio/homeostase da população em geral. Esta, para ser bem-governada, bem-conduzida, não mais pode dispensar as ações voltadas para esse segmento da população que é o infantil.

Como se pode perceber, estou trabalhando sobre uma plataforma que articula infância e poder, que, ao mesmo tempo, se afasta da ideia de que tal relação sempre existiu e que teria sido sempre a mesma. No nosso caso, pensamos o poder como o aparecimento de um direito de intervir para fazer viver, de intervir sobre a maneira de viver e sobre o "como" da vida.

A partir da ideia de poder que intervém sobre todo esse nível para ampliar a vida, para controlar os acidentes, o aleatório, as deficiências, enfim, para retardar o término da vida. Este último efeito evidencia o extremo do poder e, poderíamos imaginar que, para atingi-lo o mais plenamente possível, o poder deveria ser exercido antes mesmo da vida, como nos controles sobre nupcialidades e casamentos a que nos referimos, por exemplo; e se fazer presente desde a mais tenra idade, ao que temos assistido com a institucionalização geral da criança pequena.

Para finalizar, proponho um looping, uma volta ao começo deste artigo. Se entendemos a infância como uma ideia construída com base em um sistema normativo, analisar aspectos do discurso médico sobre a infância e das idades da vida, e outras racionalizações e formas de exercício de poder sobre os corpos e sobre as populações, foi uma tentativa de dar a ver parte desse sistema regulatório que inventou e atualiza ideias de infância que legitimamos e reproduzimos. Em linhas grossas, ainda estamos dentro do regime pitagórico, que repartiu a vida em etapas. Para ele, eram quatro: criança, muito jovem, jovem e idoso, cada qual com duração de 20 anos. Não interessa discutir o número nem a designação das etapas da vida. Não é o caso de arbitrar sobre o arbitrário. $\mathrm{O}$ fato é que estamos presos a essa verdade, independentemente do modo como segmentamos a vida. Parece que uma problematização desse esquema, libertar-se dessa norma, é tarefa impossível ou destinada ao esquecimento, como o que ocorreu com a problematização de Sêneca a 
respeito do regime pitagórico.

Em desacordo com os que repartiam a vida em fatias, Sêneca propôs considerar a vida como uma espécie de unidade dinâmica: unidade de um movimento contínuo que tenderia para a velhice. Velhice que passava a ser descrita como um lugar que ofereceria um abrigo seguro. A velhice não seria apenas parte de uma cronologia, unicamente amarrada nas voltas que a terra dá em torno do Sol e no modo como medimos e repartimos esse ciclo, essa repetição. A velhice deveria corresponder a um tempo ideal da vida que, de certo modo, fabricamos e para o qual nos preparamos. No fundo, nessa nova ética,

É preciso que, a cada momento, mesmo sendo jovens, mesmo na idade adulta, mesmo se estivermos ainda em plena atividade, tenhamos, para com tudo que fazemos e somos, a atitude, o comportamento, o desapego e a completude de alguém que já tivesse chegado à velhice e completado sua vida. (FOUCAULT, 2004, p. 137)

Nessa espécie de redescrição da vida, o idoso seria aquele que se apraz consigo e, a velhice, quando bem-preparada por uma longa prática de si, seria o ponto em que $o \mathrm{eu}$, como diz Sêneca, finalmente teria atingido a si mesmo, em que teria se reencontrado, tendo para consigo uma relação acabada e completa, de domínio e de satisfação (FOUCAULT, 2004, p. 135).

O projeto de Sêneca, milenar, de "unidade dinâmica" e da "velhice como ponto desejável", parece não ter sido bem-sucedido, pois a classificação da vida permanece apegada ao regime pitagórico, descrita por meio de ciclos, etapas, momentos, fases, níveis, estágios e períodos. Tais termos, mutáveis e intercambiáveis, não deixam de remeter e reforçar a tese de que é possível, valendo-se de recursos variados, reconhecer aspectos comuns nas diferentes partes da vida assinaladas pelos ponteiros do relógio, por algo externo ao próprio homem e que, a cada uma dessas frações, corresponderia um modo, um "como" de vida particular. É, portanto, no interior dessa crença que a ideia de infância vem sendo formulada e reproduzida, acoplada à criação e à reordenação de instituições que passaram a ser estreitamente vinculadas à etapa "mais tenra da vida".

Essa invenção dos adultos, essa racionalização da vida, essa espécie de saber-poder sobre a vida talvez ajude a compreender a crítica e a tristeza de James Barrie, em uma das mais belas e contundentes críticas 
ao mundo dos adultos. No início do século XX, em 1904, na Inglaterra, atordoado com o que a civilização produzia, ele escreveu Peter Pan, texto que foi objeto de uma difusão espetacular, como sabemos. No início da história, ele sentencia "todas as crianças, exceto uma, crescem. (...) Wendy sabe que teria que crescer. A gente sempre tem consciência disto depois de dois anos. Dois anos: isto é o começo do fim" (BARRIE, 2004).

\section{Referências}

AROLES, Serge. L'énigme des enfants-loups - Une certitude biologique mais un deni des archives (1304-1954). Paris: Publibook, 2007.

BANKS-LEITE, Luci; GALVÃO, Izabel (Orgs). A educação de um selvagem - as experiências pedagógicas de Jean Itard. São Paulo: Cortez, 2000.

BARRIE, James. Peter Pan. São Paulo: Ediouro, 2004.

BECCHI, Egle; JULIA, Dominique. Histoire de l'enfance, histoire sans paroles? In: Histoire de l'enfance en Occident - de l'antiquité au XVII siècle, v. I. Paris: Seuil, 1998.

BECCHI, Egle. Le XIX siècle. In BECCHI, Egle; JULIA, Dominique. Histoire de l'enfance en Occident - du XVIII siècle à nos jours, v. II. Paris: Seuil, 1998.

BECQUEREL, A. Traité elementaire d'bygiene privée et publique. 3 ed. Paris: P. Asselin, 1864. BOUTIER, Jean ; PASSERON, Jean Claude; REVEL, Jacques (Orgs.). Qu'est-ce qu'une discipline? Paris: EHESS, 2006.

CHASSAGNE, Serge. Le travail des enfants aux XVII e XIX siècles. In: BECCHI, Egle; JULIA, Dominique. Histoire de l'enfance en Occident - du XVIII siècle à nos jours, v. II. Paris: Seuil, 1998.

CHAUVIN, Danièle (Org.). L'imaginaire des âges de la vie. Grenoble: Ellug, 1996.

CONDORCET, Jean. Cinco memórias sobre a instrução pública. São Paulo: EdUNESP, 2008. FÉNELON, François de Salignac de la Mothe. Da educação das meninas. Paris: Typographia de Fillet Fils Ainé, 1852.

FÉNELON, François de Salignac de la Mothe. De l'éducations des filles. Première version. In LE BRUN, Jacques. Fénelon - Oeuvres. Paris: Gallimard, 1983.

FOUCAULT, M. Microfísica do Poder. Rio de Janeiro: Graal, 1988.

FOUCAULT, M. Vigiar e Punir. 9 ed. Petrópolis: Vozes, 1991.

FOUCAULT, M. Em defesa da sociedade. São Paulo: Martins Fontes, 2000.

FOUCAULT, M. Os anormais. São Paulo: Martins Fontes, 2002.

FOUCAULT, M. A hermenêutica do sujeito. São Paulo: Martins Fontes, 2004.

FOUCAULT, M. O poder psiquiátrico. São Paulo: Martins Fontes, 2006.

FOUCAULT, M. Segurança, Território, População. São Paulo: Martins Fontes, 2008a.

FOUCAULT, M. Nascimento da biopolitica. São Paulo: Martins Fontes, 2008b.

GÉLIS, Jacques. A individualização da criança. In: ARIĖS, Philippe; CHARTIER, Roger (Orgs.) História da vida privada - da Renascença ao Século das Luzes. v 3. 6 reimp. São Paulo: Companhia das Letras, 1997.

GONDRA, José G. "Modificar com brandura e prevenir com cautela": racionalidade médica e higienização da infância. In: FREITAS, M.; KUHLMANN JR. Os intelectuais na 
bistória da infância. São Paulo: Cortez, 2002.

GONDRA, José G. Artes de civilizar - medicina, higiene e educação escolar na Corte Imperial. Rio de Janeiro: Eduerj, 2004.

GONDRA, José; GARCIA, Inára. Arte de endurecer "miolos moles e cérebros brandos" - racionalidade médico-higiênica e a construção social da infância. Revista Brasileira de Educação. Campinas: Autores Associados, n. 26, p. 69-83, mai/ago. 2004.

LE BRUN, Jacques. Fénelon - Oeuvres. Paris: Gallimard, 1983.

LUC, Jean-Noël. Les premières écoles enfantines et l'invention du jeune enfant. In BECCHI, Egle; JULIA, Dominique. Histoire de l'enfance en Occident-du XVIII siècle à nos jours, v. II. Paris: Seuil, 1998.

MONCORVO FILHO. Allocução por occasião da inanguração do edifício do Instituto de Proteção a Infancia do Rio de Janeiro. Rio de Janeiro: Empreza Graphica Editora \& Paulo, Pongetti \& C., 1931.

PEIXOTO, Afrânio. Higiene. 2 ed. Rio de Janeiro: Francisco Alves, 1917.

PEIXOTO, Afrânio. Elementos de medicina legal. Rio de Janeiro: Francisco Alves, 1910.

SAHLINS, Marshal. Como pensam os nativos. São Paulo: Edusp, 2001.

\section{Notas}

1 Este tipo de afirmação parece se generalizar no meio acadêmico, como dá a ver a apresentação do I Seminário de Grupos de Pesquisa sobre Crianças e Infâncias: Tendências e Desafios Contemporâneos, ocorrido na Universidade Federal de Juiz de Fora, entre 25 e 27/9/2008, assinada por Eliane Medeiros Borges - UFJF, Jader Janer Moreira Lopes UFF e Léa Stahlschmidt Pinto Silva - UFJF. Conferir texto integral em http://www.grupeci.ufjf.br/apre.htm (acesso em 18 de setembro de 2008).

2 Como se organizou essa forma de pensar a vida? Essa forma de classificação interna da vida? Que forças e agentes participaram desse esforço? Que efeitos tal representação produz? É possível instaurar uma diferença em relação a esse modo de pensar o homem e a vida?

3 Para um aprofundamento dessa questão, cf. Gondra (2000) e Gondra e Garcia (2004). 4 Sir Kelnem Digby, um dos fundadores da Royal Society, foi um dos primeiros a mencionar Jean de Liége, em 1644. Com cinco anos, durante um período de guerras religiosas, Jean refugiou-se na floresta com outros aldeões. Quando a guerra esfriou, enquanto os outros retornaram para suas casas, Jean se perdeu e ficou desaparecido por dezesseis anos. Vivendo na floresta, seus sentidos aguçaram-se: ele podia sentir o cheiro de frutas e raízes a grande distância. Foi resgatado aos 21 anos: estava nu. Seus cabelos, muito compridos, cobriam-lhe o corpo e era incapaz de falar. De volta ao convívio com humanos, reaprendeu a falar, mas nunca perdeu o olfato apurado

5 A primeira publicação moderna considerada histórica sobre essa "criança selvagem" foi o trabalho do médico Phillipus Camerius, publicado em Frankfurt, em 1609. Ali são descritos os casos de "Hesse wolf-child" (menino-lobo) e "Bamberg-calf" (meninobezerro), este, “...possuía pernas extraordinariamente flexíveis e andava usando os quatro membros com grande agilidade. Nessa postura, ele enfrentava, em luta, cães de grande 
porte, usando os dentes. Apesar disso, era dócil com humanos; não possuía uma natureza feroz".

$\mathbf{6}$ Ele foi trazido a Amsterdam. ...Era um jovem de 16 anos que tinha se perdido dos pais. Crescendo entre as ovelhas e os carneiros selvagens da Irlanda, adquiriu um tipo de "natureza ovina". Tinha movimentos rápidos, ágil com os pés, expressão fisionômica bravia, carnes firmes, pele queimada, trigueira, pernas e braços rígidos, destemido e destituído de qualquer delicadeza. A saúde era excelente. Não conhecia a voz humana; emitia balidos, como as ovelhas. Sua garganta era larga e a língua parecia presa no palato. Recusava alimentos comuns; estava acostumado a comer gramíneas e feno. Viveu em montanhas e lugares desertos, como cavernas, locais distantes de qualquer centro de civilização. Os caçadores que o encontraram disseram que ele parecia um animal e não um ser humano. Obrigado a viver como gente, a contragosto e somente depois de muito tempo ele começou a perder suas características selvagens. (Nicholaus Tulp: Observationes Medicae, 1672).

7 A menina de Kranenburg foi achada em 1717, na floresta, próxima à província de Overyssel, Alemanha. Foi sequestrada aos 16 meses, levada da casa de sua família em Kranenburg. Ao ser resgatada, estava vestida com pano grosseiro e alimentava-se de folhas e grama. Não havia qualquer evidência de que tivesse sido adotada por algum tipo de animal. Ela aprendeu a trabalhar com fiação, a se comunicar por meio de sinais, mas nunca conseguiu falar normalmente.

8 O primeiro caso de criança selvagem que ganhou fama foi "Wild Peter". Quando foi descoberto, estava nu, tinha a pele escurecida e os cabelos negros crescidos e emaranhados. Capturado em Helpensen, Hanover, em 27 de julho de 1724, aparentava ter 12 anos na ocasião. Subia em árvores com extrema facilidade. Não falava, recusava-se a comer pão e preferia consumir ramos verdes de certos vegetais, que mascava e sugava. Mais tarde, aceitou frutas e verduras de horta. Foi exibido em Hanover na corte de George I. Levado para a Inglaterra, ali foi estudado pelos cientistas. Viveu 68 anos em sociedade, mas nunca aprendeu a dizer nada além de "Peter" e "rei George".

9 Em 1731, uma menina aparentando 10 anos foi encontrada em uma árvore em Songi - Chalons, distrito de Champagne, França. Estava descalça, com o vestido reduzido a trapos e um gorro feito de folhagens na cabeça. Em uma espécie de bolsa, guardava um porrete e uma faca, na qual distinguiam-se caracteres indecifráveis. Emitia gritos agudos. Sua pele estava tão suja e escurecida que alguns acharam que era uma menina negra. Comia passarinhos, sapos e peixes, folhas, brotos e raízes. Quando colocaram um coelho em sua frente, ela imediatamente o matou, abriu sua entranhas e comeu sua carne. A garota de Champagne é um dos raros casos de criança selvagem que aprendeu a falar coerentemente, o que faz pensar que, antes de ser abandonada ou perder-se, já sabia falar. Em pouco tempo, ela esqueceu a maior parte de sua vida na floresta, que, supõe-se, durou cerca de dois anos. "Seus dedos, especialmente os polegares, eram extraordinariamente largos" - relatou uma testemunha da época, o famoso cientista Charles Marie de la Condamina. Ela usava esses dedos para extrair raízes e como apoio para se agarrar nos ramos das árvores, entre as quais movia-se como um macaco. Era muito rápida na corrida e tinha uma visão fenomenal. A menina recebeu o nome de Marie-Angélique Memmie le Blanc. Cresceu e se estabeleceu em Paris, onde trabalhava no artesanato de 
flores artificiais. Suas memórias foram escritas por Madame Hecquet. Morreu na obscuridade, como a maioria das crianças selvagens. Informações extraídas do site http:/ / sofadasala.vilabol.uol.com.br/noticia/feralchildren.htm. Acesso em 18 de setembro de 2008.

10 Há mesmo quem desconfie da existência de muitos desses seres (meninos lobos, meninas gazelas,...), como aparece no recente trabalho de Aroles (2007).

11 Reconhecendo uma espécie de banalização do conceito de cultura, como se estivesse no "crepúsculo de sua carreira", Sahlins (2001) entende essa categoria como um termo que se presta para descrever formas específicas de vida que, sendo diferentes, empregam racionalidades próprias. Nesse sentido, cultura e civilização não podem ser vistos como análogos. Para ele "civilização", termo empregado na França na década de 1750 e rapidamente adotado na Inglaterra, funcionou para que ambos pudessem explicar suas realizações superiores e justificar suas ações imperialistas: "O significado não era o mesmo que o sentido de 'cultura' enquanto modo de vida, que é agora próprio da antropologia. Entre outras diferenças, 'civilização' não era passível de pluralização: não se referia aos modos distintos de existência de diferentes sociedades, mas à ordem ideal da sociedade humana em geral" (2001, p. 25).

12 Criada em 1881 pelo Dr. Moncorvo de Figueiredo. Com sua morte, em 1901, o filho assume a direção da Policlínica.

13 Para maior desenvolvimento dessa questão, cf. Boutier, Passeron e Revel (2006).

14 Para aprofundamento dessa reflexão, cf. Foucault (1988; 1991; 2000; 2002; 2004; 2006; 2008 ; 2008b).

Recebido: $27 / 10 / 2009$

Aprovado: 25/11/2009

Contato:

Universidade do Estado do Rio de Janeiro

Faculdade de Educação

Programa de Pós-Graduação em Educação Rua São Francisco Xavier, 524 - sala 12037- Bloco F

Maracanã

CEP 20550-013

Rio de Janeiro/RJ 